\title{
Hombres que ejercen violencia contra las mujeres: un análisis interdisciplinar
}

\author{
Men who exercise violence against women: \\ an interdisciplinary analysis
}

IVÁN SAMBADE ${ }^{1}$ (Universidad de Valladolid)

Artículo recibido: 19 de junio de 2021

Solicitud de revisión: 24 de junio de 2021

Artículo aceptado: 6 de octubre de 2021

Sambade, Iván (2021). Hombres que ejercen violencia contra las mujeres: un análisis interdisciplinar. Recerca. Revista de Pensament i Análisi. Publicación en avance. doi: http://dx.doi.org/10.6035/recerca.6022

\section{Resumen}

Este artículo es una revisión de uno de los estudios más relevantes sobre los hombres que ejercen violencia machista realizados desde la psicología social y la teoría del apego, a la luz de la filosofía política y la sociología feminista del conocimiento. Propone, por lo tanto, una apuesta por el enfoque interdisciplinar en el estudio de la conducta humana. Desde este enclave, el trabajo se centra en el análisis de las relaciones sistémicas entre el estado vigente de la estructura patriarcal de poder, la socialización de género de los hombres y la violencia machista contra las mujeres.

Palabras clave: masculinidad hegemónica, violencia machista, patriarcado, igualdad, interdisciplinariedad.

\section{Abstract}

This article is a review of one of the most relevant studies on men who exercise sexist violence carried out from Social Psychology and Attachment Theory in the light of Political Philosophy and Feminist Sociology of Knowledge. Therefore, it proposes a commitment to the interdisciplinary approach in the study of human behavior. From this perspective, the present work focuses on the analysis of the systemic relationships between the current state of the patriarchal power structure, the gender socialization of men and sexist violence against women.

\footnotetext{
${ }^{1}$ ivansambade@gmail.com
} 
Key Words: hegemonic masculinity, sexist violence, patriarchy, equality, interdisciplinarity.

\section{INTRODUCCIÓN}

El protagonismo de la conducta antisocial por parte de los hombres es un hecho estadísticamente inobjetable (Clare, 2002). Diferentes ciencias han investigado las causas de la disposición de los hombres hacia el ejercicio de la violencia. Desde la psicología evolucionista sigue existiendo una obstinada defensa de la tesis de la determinación biológica de la conducta violenta de los hombres. Pero, contrariamente, ciencias cuya metodología exige una sólida base empírica de contrastación, como la neuropsicología (Walter, 2010), la neuroendocrinología (Sapolsky, 1997) o la biología evolucionista (Gowaty, 2008), han demostrado que los factores socioculturales son más decisivos que los biológicos en el desencadenamiento de la violencia masculina.

Un caso específico de violencia que ejercen los hombres en el que se puede observar con claridad su condicionamiento sociocultural es la violencia de género. Desde hace tres décadas, existen estudios de psicología y teoría del apego que han puesto de manifiesto la influencia de la cultura patriarcal en el ejercicio de la violencia contra las mujeres. Esta perspectiva ha resultado valiosa no solo por sus resultados, sino porque revisiones posteriores han mostrado que el análisis de las violencias machistas requiere de un enfoque de investigación más amplio; un enfoque ecológico, multicausal e interdisciplinar (De Alencar-Rodrigues y Cantera, 2012).

Este artículo tiene el objetivo de mostrar cómo las aproximaciones desde ciencias como la filosofía política y la sociología feminista del conocimiento pueden enriquecer la comprensión de fenómenos conductuales que han sido analizados exclusivamente desde la psicología. Por lo tanto, apoya e intenta fundamentar la apuesta por la interdisciplinariedad como presupuesto básico del estudio de la conducta humana. Simultáneamente, presentamos un análisis filosófico y sociológico sobre la influencia de la estructura patriarcal de poder en la socialización de los hombres, con el objetivo de mostrar la interrelación sistémica de la violencia machista contra las mujeres con el estado vigente de la desigualdad sociopolítica entre los sexos. Como resultado, llegaremos a la conclusión de que la desigualdad de género no solo es una fuente de injusticia contra las mujeres, sino también de frustración e infelicidad para los propios hombres. 


\section{HOMBRES QUE EJERCEN VIOLENCIA CONTRA LAS MUJERES: UNA APROXIMACIÓN DESDE LA PSICOLOGÍA SOCIAL Y LA TEORÍA DEL APEGO}

Desde la sociología, se ha señalado que no existe un perfil sociológico de maltratador de mujeres. La observación empírica de hombres condenados por el ejercicio de violencia en las relaciones afectivas heterosexuales de pareja ha puesto de manifiesto que estos no difieren de la normalidad masculina general (Ferreira, 1992). Pueden ser simpáticos y seductores y tener actitudes de ciudadano modelo, lo que dificulta la sospecha sobre las conductas delictivas que ejercen en la intimidad. El maltratador puede pertenecer a cualquier clase social, etnia o afiliación religiosa. Por estos motivos, su característica principal es la doble fachada: el desarrollo de conductas disímiles y contradictorias en relación con su situación, bien en la esfera pública o bien hacia su pareja afectiva en la esfera privada.

Por otra parte, a pesar de que, desde las ciencias de la conducta, se ha descartado que los maltratadores de mujeres padezcan enfermedad mental alguna (Lorente, 2001), se han realizado múltiples estudios con el objetivo analizar sus características psicosociales. Una de las teorías más influentes en el ámbito de la psicología social fue propuesta por Donald Dutton y Susan Golant (1997). Estos especialistas especifican tres factores decisivos en la configuración de la personalidad del maltratador machista: a) el rechazo y el maltrato del padre, b) el apego inseguro de la madre y c) la influencia de la cultura machista.

a) La mayoría de los agresores analizados por Dutton y Golant habían sufrido malos tratos físicos y emocionales por parte de su padre durante la infancia. De este modo, el sentimiento de culpabilidad experimentado frente al rechazo del padre habría afectado a su empatía y a sus capacidades de autorregulación y de gestión de la ansiedad y de la ira con sus parejas durante la madurez.

b) El segundo factor se centra en el desarrollo de la autonomía del niño. Esta se adquiere en un proceso de separación/individuación respecto de la madre, en el que el menor sigue necesitando de un afecto que, simultáneamente, le permita explorar el mundo con seguridad. La carencia de apego seguro durante la infancia provocaría más probabilidades de dependencia emocional $\mathrm{y}$ ansiedad frente a la ausencia y la separación durante la madurez. En consecuencia, los maltratadores ejercerían el control de sus parejas como un intento de gestionar el trauma generado por la experiencia de un acercamiento fallido con su madre durante la infancia. 
c) Finalmente, la cultura tiene una doble función en la génesis de las conductas violentas de los maltratadores. En primer lugar, en las sociedades patriarcales los niños son socializados en la masculinidad normativa desde la infancia. En este proceso, integran en su subjetividad las exigencias de reprimir emociones como el miedo y la inseguridad, para transformarlas en un sentimiento de ira que aprenden a canalizar a través del ejercicio de la violencia. En segundo lugar, una vez formada la personalidad, algunos hombres recurren a la cultura patriarcal para justificar su violencia, precisamente en la medida en que la sociedad naturaliza su ejercicio como una forma de resolver conflictos.

Dutton y Golant (1997) establecen una clasificación con tres perfiles psicológicos de maltratadores machistas:

1) El maltratador cíclico o emocionalmente inestable

Son hombres que se caracterizan por su baja autoestima y su inestabilidad emocional. Necesitan tener pareja para sentirse seguros, de modo que desarrollan dependencia funcional de la misma. Tienen una marcada interiorización de los roles de género, especialmente del rol de proveedor, entendiendo su trabajo como una fuente de éxito social. De este modo, la posición laboral y social de su pareja puede afectar a su concepto de sí mismos y su autoestima.

Manifiestan recelo a la hora de expresar sus sentimientos y consideran que los problemas de pareja deben resolverse en la intimidad. La ira aparece como una forma de reprimir el miedo, la inseguridad o el rechazo; sentimientos inaceptables para su idea de masculinidad. Asimismo, la violencia surge como una estrategia de recuperación del control, pero no son personas obsesionadas con el mismo. Experimentan arrepentimiento y miedo frente a las consecuencias de sus actos, pero no se reconocen como maltratadores machistas. El arrepentimiento aparece como sentimiento exculpatorio.

Dutton y Golant (1997) los denominan golpeadores e indican que este modelo de maltratador machista es el modelo predominante, alcanzando un porcentaje cercano al 70 \% de los casos.

2) El maltratador psicopático o psicópata

Son personas que normalizan la violencia, tanto la recibida durante la infancia como la que ellos ejercen durante su madurez. La agresividad es su pauta habitual de conducta y no sienten culpa ni arrepentimiento. Al contrario, se sienten sometidos a la persecución y el hostigamiento de los demás, lo que creen que justifica sus impulsos malvados.

Dutton y Golant (1997) los denominan velociraptors: personas que actúan como deportistas entrenados, ejerciendo violencia con calma interior, aunque 
aparenten estar en un elevado nivel de excitación. Encuentran tranquilidad en la actitud de alerta y en el ejercicio de control de otras personas, pero no sienten dependencia de ellas. Son autónomos y desconfiados. Se sienten superiores y desempeñan estrategias de seducción cuando lo necesitan.

Tienen una marcada interiorización de los roles de género. De este modo, mientras que se identifican con el trabajo como fuente de autonomía, desconfían permanentemente de que su pareja cumpla adecuadamente las funciones tradicionalmente asignadas a las mujeres: el cuidado, el trabajo doméstico y la administración de la economía familiar. De hecho, creen en la inferioridad biológica de las mujeres y en los roles laborales sexuados. Dada su psicopatía, podrían ejercer maltrato con cualquier persona independientemente del sexo, pero su interiorización de las creencias de género les predispone a hacerlo contra las mujeres.

3) El maltratador hipercontrolador

Son hombres que aparentan estar disociados de sus sentimientos, con alto nivel de evitación y conducta pasiva-agresiva. La ira emerge como consecuencia de la acumulación progresiva de frustraciones ocasionadas por aquello que no pueden controlar. Son personas meticulosas, perfeccionistas y dominantes.

Tienen una alta interiorización de los roles de género. En particular, el trabajo es el eje central de su autoconcepto, comprendiéndolo como aquella actividad que les ha permitido construirse a sí mismos hasta el punto de superarse. En consecuencia, suelen ejercer violencia económica, emocional y social contra sus parejas, infravalorándolas constantemente en relación con sus roles femeninos. Como su rol fundamental es el de proveedor, desconfían constantemente de la capacidad de administración del dinero de su mujer, sintiendo la necesidad de controlarlo e incluso creyendo que su pareja les engaña. Estas ideas justifican la aparición de las conductas violentas, las cuales estarían destinadas a disciplinar a sus mujeres para que cumplan su deber femenino. Se justifican, por lo tanto, arguyendo su sentido androcéntrico del deber, de modo que, cuando son castigados, se sienten engañados y víctimas de sus mujeres. Aun así, no se suelen plantear el abandono de la relación.

Las principales objeciones a la teoría de Dutton y Golant se basan en la centralidad que tiene la relación de apego con los progenitores durante la infancia. Como ha señalado Dohmen (1996), la violencia sufrida en la infancia y la ejercida durante la edad adulta se encuentran en momentos evolutivos diferentes. De hecho, muchos hombres que fueron maltratados durante la infancia no son maltratadores en su edad adulta. Frente a esta objeción, Dutton y Golant se vieron obligados a conceder más importancia a la influencia de la cul- 
tura patriarcal. Este matiz estaba implícito en el hecho de que los tres perfiles de maltratador machista tienen una sólida aceptación de los roles de género. Ahora bien, el peso específico de la cultura patriarcal como elemento permanente del proceso de socialización pone de manifiesto que el estudio exclusivamente psicológico no es suficiente para explicar la masculinidad violenta. Esta se explica mejor desde un enfoque interdisciplinar, multicausal y ecológico (De Alencar-Rodrigues y Cantera, 2012). Este enfoque elimina el determinismo del trauma infantil, de modo que las experiencias vividas durante la infancia no determinan completamente la conducta. Además, es importante tener en cuenta que la cultura patriarcal no solo condiciona la conducta del futuro maltratador mediante la disposición de sus progenitores como modelos sociales de género, sino que las propias prácticas mediante las que se establece el vínculo de apego están generizadas, lo que determina el sesgo androcéntrico de la psique y la conducta del menor. Un ejemplo esclarecedor en este sentido sería la conducta de un padre que, sin estar ausente ni maltratar al menor ni a la madre, fortalece sus vínculos a través de los roles tradicionalmente masculinos, como la complicidad con las conductas violentas del menor, cuando este las justifica como medio de autoprotección. El menor verá un igual en su padre, en tanto que hombre, con quien comparte un código moral común. Si la vida familiar está estructurada conforme a la división sexual del trabajo, de modo que el vínculo de apego con su madre se establece a través de las prácticas de cuidado que esta ejerce, el menor no verá en su madre a una igual, sino a un ser para otro, empleando la expresión de Simone de Beauvoir. Obviamente, en el caso de que el padre sea efectivamente un maltratador, las disposiciones hacia la violencia del menor en el futuro estarán siendo originadas tanto por el trauma ocasionado como por la cultura patriarcal.

La relevancia de la cultura patriarcal en el proceso de socialización nos permite reinterpretar los factores mencionados por Dutton y Golant:

a) A los traumas generados durante la infancia por la violencia del padre, hay que añadirle que la socialización en la masculinidad hegemónica patriar$\mathrm{cal}^{2}$ sobreestimula a los hombres para que arriesguen su integridad y transgre-

\footnotetext{
${ }^{2}$ El concepto de masculinidad hegemónica fue acuñado por Raewyn Connell (1995; 2005), mientras que la configuración patriarcal de masculinidad ha sido estudiada por David Gilmore (1994). Gilmore caracteriza la masculinidad patriarcal por tres exigencias sociales (provisión, protección y procreación), cuyo correlato son los privilegios patriarcales: reconocimiento sociolaboral, legitimidad social en el ejercicio de la violencia y doble moral sexual. La doble adjetivación se ha realizado bajo el objetivo de poner de manifiesto que la configuración patriarcal de masculinidad sigue siendo socialmente hegemónica (luego, normativa) en nuestras democracias modernas, a pesar de que el patriarcado ha sido impugnado por el movimiento feminista en su lucha de democratización social. Esta resistencia frente a la transformación
} 
dan las normas. De hecho, los hombres desarrollan psicopatías en un porcentaje muy superior al de las mujeres (Clare, 2002).

b) La madre no tiene por qué ser la única figura de apego seguro. La vinculación del apego seguro con la madre supone la asunción implícita de un modelo normativo de femineidad, fundado en la división sexual del trabajo, que responsabiliza exclusivamente a las mujeres del cuidado y la crianza de hijas e hijos. Si la masculinidad normativa implicara al padre de forma equitativa en estas funciones, este también sería responsable de transmitir un apego inseguro en su caso.

c) La cultura masculina del riesgo y la violencia se desarrolla por medio del autocontrol disciplinario de las emociones feminizadas por la cultura patriarcal (Sambade, 2020; 2014). Esto no solo dispone a los hombres a infravalorar los riesgos para su propia salud, sino que también les induce un sentimiento misógino que pone a las mujeres en el punto de mira de sus conductas violentas, más aún cuando su implícito objetivo es confirmar una masculinidad que se define culturalmente sobre la minusvaloración de las mismas (Hernández y Cuellar, 2019).

En resumen, el enfoque interdisciplinar del estudio de los maltratadores machistas nos ofrece una explicación más amplia sobre las causas de sus conductas violentas; una teoría multicausal en la que la socialización patriarcal adquiere una relevancia decisiva. Esto nos permite explicar satisfactoriamente algún contraejemplo a la teoría de Dutton y Golant, como los casos de aquellos hombres que no son violentos habiendo padecido maltratos durante su infancia. La participación en su proceso de socialización de otras personas que les hayan aportado un apego seguro, mostrando al mismo tiempo una norma de conducta igualitaria, podría haber provocado una integración funcional de sus frustraciones, desviándolos de la violencia misógina. Asimismo, los propios Dutton y Golant (1997) sostienen que la reeducación cognitiva, el apoyo de la familia y del grupo de iguales y la terapia psicológica son factores que influyen positivamente en la resocialización de personas que han padecido experiencias traumáticas durante su infancia.

A continuación, analizaremos la socialización de los hombres en la masculinidad hegemónica patriarcal a la luz de las coordenadas que aportan disciplinas como la sociología feminista del conocimiento, la antropología cultural, la filosofía política y la psicología social. 


\section{UNA MIRADA FILOSÓFICO-FEMINISTA SOBRE EL CONTEXTO HISTÓRICO Y SOCIAL}

A finales del siglo pasado, y como consecuencia de las luchas feministas internacionales, las sociedades occidentales llevaron a cabo un conjunto de reformas legales en favor de la igualdad efectiva de la ciudadanía de mujeres y hombres. En consecuencia, se produjeron una serie de transformaciones en las estructuras de poder de sexo-género que la sociología denominó la crisis del patriarcado (Marqués, 1991). Los cambios sociales impulsados por las políticas feministas produjeron asimismo reacciones diversas entre los hombres. La disminución de los privilegios sociales patriarcales tuvo, en primer lugar, una reacción de resistencia por parte de los mismos no exenta de complicidad social, hasta el punto de que la cultura popular interpretó la violencia masculina como una consecuencia del acecho que las políticas feministas les estaban infringiendo (Segal, 2008). Contrariamente, las ciencias sociales coincidieron en señalar que la prevalencia de los hombres en el ejercicio de la conducta antisocial solo podía ser entendida como una crisis de la masculinidad normativa (Clare, 2002). El acceso masivo de las mujeres al mercado laboral habría generado una situación de resistencia agresiva por parte de los hombres, quienes experimentaron la transformación de los espacios sociales antaño exclusivamente masculinizados como un atentado contra su identidad. Asimismo, otras casuísticas sociales, como las altas proporciones de suicido masculino (Gutiérrez-Barroso, Barragán-Medero y Pérez-Jorge, 2018), de drogadicciones, de accidentes de tráfico, de accidentes laborales, de fracaso escolar, etc., entre los hombres, fueron interpretadas como un síntoma de la disfuncionalidad social de la masculinidad normativa (Clare, 2002): la masculinidad hegemónica patriarcal (Connell, 1997). En síntesis, la democratización social feminista no habría provocado transformaciones de las masculinidades hacia la igualdad (salvo en una proporción minoritaria), sino que estas se han ido reestructurando conforme al conflicto social vigente.

La socialización de los hombres en el modelo hegemónico de masculinidad se ha reproducido en gran medida como consecuencia de su invisibilidad. Amelia Valcárcel (2008) ha explicado que la sobrevaloración social de los cambios económicos y legislativos en favor de la igualdad ha provocado la falsa conciencia social de que la igualdad es un hecho, lo que impide que la ciudadanía perciba la persistencia de múltiples formas de desigualdad y discriminación de las mujeres. Es la ficción de igualdad (Valcárcel, 2008). Así, la estructura social patriarcal, aun deslegitimada, sigue proporcionando a los hombres una serie de privilegios socia- 
les respecto de las mujeres: mayor reconocimiento y credibilidad social; una educación desigual en lo que se refiere al trabajo doméstico, la proyección profesional y los usos del tiempo libre; mayor acceso a los contextos informales del mundo laboral; más libertad sexual y menos estigmas sociales sexuales; etc. Son los dividendos patriarcales (Connell, 1997). En este contexto, muchos hombres pueden haber adoptado una ideología igualitaria, incluso tener conciencia feminista, pero siguen ejerciendo diversas estrategias invisibilizadas de discriminación/dominación de las mujeres: micromachismos (Bonino, 1998). Por lo tanto, la crisis de los patriarcados modernos no ha supuesto la desaparición del privilegio masculino, sino que, impugnado por una opinión pública más sensible hacia la desigualdad, se ha reproducido soterradamente a través de la aceptación superficial de la ideología igualitaria y del desarrollo de estrategias de discriminación más sutiles e imperceptibles. Ahora bien, en conjunto, estas prácticas sustentan una realidad social desigual entre hombres y mujeres bajo la que se perpetúan estados de dominación machista. La violencia de género en el seno de las relaciones afectivas heterosexuales es uno de ellos.

El concepto de ficción de igualdad (Valcárcel, 2008) permite vislumbrar que las estructuras sociales patriarcales no solo están resistiendo frente a la impugnación social y política feminista, sino que se están reestructurando en lo que algunas teóricas han denominado la contrarreforma patriarcal (Puleo, 2012) o el retorno del sexismo (Walter, 2010), entre otras designaciones. Los medios de comunicación de masas, en connivencia con el sistema capitalista neoliberal, son un potente agente socializador de esta contrarreforma patriarcal. Los media proyectan una representación figuradamente equitativa de ambos sexos a través de modelos de belleza de género que, aparentemente, ostentan una posición de éxito social en nuestras sociedades informacionales de mercado. En cambio, los modelos de belleza masculina se funden con la representación del sujeto agente del relato social compartido, mientras que la sexualización de los cuerpos de las mujeres las cosifica conforme a la mirada y el placer de los hombres (Sambade, 2020). Esta redefinición de los modelos identitarios de género, que encuentra su origen en la alianza del capitalismo de consumo con la industria de sexo, ha producido la explotación de masas ingentes de mujeres en los negocios de la prostitución y la pornografía (Walter, 2010). Como ha apuntado Rosa Cobo (2017), el hecho de que la trata de mujeres con fines de explotación sexual y la prostitución hayan aumentado exponencialmente, justo después de la ganancia histórica de derechos y calidad de vida de las mujeres dentro del contrato de matrimonio, es todo un síntoma de la revitalización del patriarcado. En este contexto, la redefinición patriarcal de la masculinidad hegemónica se erige sobre la virilidad como 
asignación de género: el nuevo hombre verdadero ha de cumplir la expectativa de hiperpotencia sexual con cuantas más mujeres, mejor, llegando a ejercer la violencia como recurso si fuera necesario (Sambade, 2020). Es la masculinidad pornocopuladora-consumidora (Gómez, 2017).

Otra estrategia de adaptación de la masculinidad patriarcal a la ficción de igualdad contemporánea, bajo el objetivo de reproducir las estructuras sociales de privilegio de los hombres, se explica a partir del concepto de posmachismo, acuñado por Miguel Lorente (2009).

A diferencia del machismo, el posmachismo no es una ideología explícita (Lorente, 2009). El contexto de la posmodernidad le confiere una forma fragmentada que lo reviste de aparente neutralidad. Se presenta como un conjunto de críticas, supuestamente inconexas, dirigidas hacia las consecuencias de los cambios político-jurídicos en favor de la igualdad. La principal estrategia del posmachista es sostener que la igualdad ya está lograda y, al mismo tiempo, que las nuevas crisis sociales son consecuencias de la misma. Por ejemplo, si las personas son más individualistas, si hay más fracaso escolar, si está aumentado la violencia juvenil, etc., es porque las mujeres, ávidas de promocionarse individualmente en el mercado laboral, han abandonado el modelo de la empatía y del cuidado; el modelo de la buena madre. En conjunto y de modo tácito, estas críticas culpabilizan a las mujeres de las nuevas crisis sociales, sosteniendo subyacentemente la idea de que, en la actualidad, solo quieren obtener privilegios extras.

Lorente (2009) explica que, a pesar de su diversidad contextual, el posmachismo cuenta con un núcleo duro de poder: grupos de hombres que adoptan una posición reflexiva, dedicada a contrarrestar las conquistas feministas de igualdad social y política. Un ejemplo es el movimiento por los derechos de los hombres (Men's Rights). Estos son conscientes de que las vindicaciones feministas tienen un profundo calado social, por lo que su estrategia fundamental es adoptar una posición neutra frente a las mismas, al tiempo que se igualan con las mujeres, definiéndose como víctimas, bien de las leyes de igualdad o bien del androcentrismo residual del antiguo código legal. De este modo, suelen actuar a través de los cauces legales, denunciando acusaciones falsas de violencia de género y sentencias injustas para sus intereses como padres.

En todo caso, Lorente (2009) sostiene que existe una íntima relación entre el posmachismo y la violencia de género. El posmachismo banaliza y normaliza la violencia de género mediante una triple estrategia. En primer lugar, el posmachismo desliga la violencia machista de su causa estructural —la desigualdad social de los sexos-, presentándola como violencia familiar o doméstica de carácter bidireccional. En segundo lugar, el posmachismo responsabiliza a las 
víctimas de la violencia que los hombres ejercen contra ellas. Serían las mujeres quienes, aprovechando la cobertura legal presente, generan el caos en la relación de pareja con sus demandas injustas y excesivas, especialmente después del divorcio. En suma, los posmachistas presentan la violencia en un contexto que la atenúa, describiéndola como una reacción hasta cierto punto lógica, en circunstancias muy desfavorables (Lorente, 2009). En tercer lugar, niegan el valor instrumental que la violencia de género tiene para la reproducción del sistema de dominación masculina.

En resumen, el posmachismo no solo niega de manera concreta múltiples manifestaciones de la discriminación de género, sino que aporta numerosos argumentos a partir de los cuales los agresores machistas pueden justificarse e incluso convencerse de sus injustas y fatídicas conductas (Lorente, 2009).

Desde una perspectiva decolonial, Rita Segato ha explicado que la reproducción de la desigualdad de género en las democracias occidentales se debe a que, en realidad, la colonización patriarcal moderna no está aún superada. Estas sociedades están estructuradas a partir de una relación de «consistencia deficiente» (Segato, 2003: 253) entre dos ejes aparentemente opuestos: el eje del contrato social entre iguales, de los valores democráticos, y el eje del estatus, de las desigualdades sociales, entre las cuales, la colonización de género fue históricamente la primera y sigue constituyendo el último peldaño de la jerarquía social. Segato sostiene que la constitución de las democracias modernas ha estado contaminada desde sus orígenes por la estructura del estatus, en la medida en que el contrato entre iguales se desarrolló en el seno de la fratria, con la consiguiente exclusión de las mujeres en tanto que cuerpos colonizados por los hombres. Como consecuencia, la estructura democrática adquiere la dinámica propia de la fratria, con su lógica capitalista de alianzas versus competición, generando la inestabilidad constitutiva del sistema social. Es decir, las relaciones de contrato entre iguales coaccionan a los hombres para mostrar el tributo apropiado de las relaciones de estatus en las que se participa, bajo la amenaza de verse expulsados del orden de iguales y desplazados a una condición de subordinados dentro de un orden jerárquico constituido por una intersección de colonizaciones en relación con la raza, la clase, el género y la orientación sexual, entre otras adscripciones. En esta inestabilidad social constitutiva que exhorta a los hombres a demostrar cíclicamente su estatus, «el cuerpo genérico de la mujer se reduce para adherirse definitivamente a la función de objeto destinado al consumo en la construcción de la masculinidad» (Segato, 2003: 256). Por lo tanto, la violencia contra las mujeres no tiene como interlocutor principal a las mismas, sino a los iguales-hombres, los cuales compiten por no ser degradados en una jerarquía social de estatus que, en 
último término, se erige sobre la expropiación simbólica y material de las primeras. Como resultado, estas quedan socialmente reducidas a objetos simbólicos del estatus de género de los hombres, es decir, de su masculinidad como garantía de prestigio social.

En síntesis, para Segato, la lógica capitalista de competición-alianzas propia de la jerarquía social resultante de la intersección de colonizaciones, junto a la fratria, como estructura de socialización de los iguales en el estatus de género, son los dispositivos fundamentales de reproducción de una estructura de poder que dispone a los hombres hacia el ejercicio de la violencia machista contra las mujeres (y los hombres feminizados), como estrategia social de confirmación de la masculinidad.

\section{MASCULINIDAD, CONTROL Y VIOLENCIA CONTRA LAS MUJERES BAJO LA FICCIÓN CONTEMPORÁNEA DE IGUALDAD: UN DIAGNÓSTICO}

La socialización de los hombres en un imaginario social que les representa como la excelencia social frente a las mujeres construye su autoestima en relación con un modelo de masculinidad que precisa de la discriminación y la dominación de las mismas para poder ser confirmado. En el contexto social democrático, este modelo es un campo de frustraciones para los hombres, puesto que, amparadas por la ley, las mujeres rechazan las conductas paternalistas, autoritarias e interesadas que emanan del mismo. De este modo, la socialización en la masculinidad normativa configura personalidades endémicas, cuyas frustraciones son el resultado de la interiorización de las exigencias patriarcales ${ }^{3}$ como deseo de dominación. La violencia emerge, así, como el último recurso para la confirmación de una masculinidad concebida como posibilidad de poder sobre las mujeres (Amorós, 1992).

El concepto de pragmática masculina del control ha sido definido como un conjunto de prácticas de disciplinamiento del cuerpo y de la emotividad que, incardinadas en la subjetividad de los hombres por el proceso patriarcal de socialización, los preparan para jugar los juegos de poder social (Sambade, 2020). Esta configuración de masculinidad dispone a los hombres hacia la suje-

\footnotetext{
${ }^{3}$ Es importante hacer notar que las expectativas patriarcales son inducidas en gran medida por el grupo de iguales, ofratria, a través de su estructura de competición-alianzas por el estatus de género (Segato, 2003) o de los pactos patriarcales de fraternidad-terror, en términos de Celia Amorós (1992).
} 
ción de las mujeres, en la medida en que estas han sido históricamente discriminadas de la esfera pública y definidas como el sexo débil. En sociedades abiertamente patriarcales, como la Grecia clásica, la pragmática del control fue constituida como una forma de gobierno de sí mismo que legitimaba de facto el control de la ciudadanía, tanto en la esfera pública como en la privada (Sambade, 2020). Asimismo, en su desarrollo histórico, la pragmática del control se ha conformado también bajo la denominada lógica moderna del dominio (Plumwood, 1993). Esta hunde sus raíces en la escisión mecanicista entre cultura y naturaleza y en la asociación de este binomio jerarquizado con los binomios hombre/mujer y razón/emoción, respectivamente. En este paradigma, los hombres han sido identificados con la razón y la cultura, ostentando el sujeto universal de la especie humana, mientras que las mujeres han sido identificadas con un concepto inerte y pasivo de materia que legitima su sujeción a manos de los primeros. Plumwood (1993) explica que la lógica del dominio ejerce su colonización social a partir de dos operadores: 1) negar la dependencia de lo oprimido (sean las mujeres o la naturaleza); y 2) negar que lo oprimido sea un ser independiente y que tenga fines propios.

Ahora bien, los seres humanos no podemos ser independientes. ${ }^{4}$ De hecho, somos animales vulnerables y necesitamos de afecto y vida social para desarrollar nuestra personalidad. Es decir, somos social y afectivamente interdependientes. En este sentido, la pragmática del control induce a los hombres a negar de su identidad todo aquello que, siendo parte constitutiva de su condición humana, se identifica con la naturaleza y la femineidad: la emotividad, la fragilidad, la vulnerabilidad, etc. Por lo tanto, la masculinidad se adquiere y se confirma a partir del disciplinamiento del cuerpo y de la emotividad, entendidos como naturaleza propia que se ha de autocontrolar bajo el objetivo de controlar al otro-mujer-naturalizado. Es decir, el gobierno del otro requiere previamente de la instrumentalización del propio sujeto de dominación, frustrando, de este modo, todo el campo de desarrollo que alberga la parte reprimida de su naturaleza humana (Sambade, 2020). Al mismo tiempo, la percepción de las mujeres como seres dependientes, como una carga frente a la independencia masculina, proyecta sobre las mismas las frustraciones provocadas por la instrumentalización de la propia subjetividad, disponiendo su sujeción como el recurso encaminado para la superación de tales frustraciones.

\footnotetext{
${ }^{4}$ La noción de independencia se emplea en el lenguaje coloquial como sinónimo de autonomía. Este uso es profundamente equívoco, pero funcional para la estructura patriarcal.
} 
En la medida en que la pragmática del control, como gobierno de sí, está estructuralmente dispuesta para obtener poder sobre las mujeres (y otras personas de humanidad negada por su identificación con la naturaleza: homosexuales, pueblos colonizados, etc.), la ocupación de posiciones sociales de poder y privilegio sobre las mismas se convierte en una fuente superficial de estabilidad emocional y autoestima para los hombres. Si invertimos el orden de esta ecuación, nos encontramos con que la estabilidad emocional y la autoestima de los hombres se sustentan sobre la capacidad de sujeción de las mujeres. La consecuencia de esta construcción es que los hombres interiorizan el ejercicio del control de las mujeres como un medio para superar sus frustraciones, independientemente de que estas hayan tenido o no algo que ver con ellas. ${ }^{5}$ De este modo, cuando un hombre que se ha identificado con la masculinidad normativa experimenta una frustración como consecuencia de su posición social o laboral, es muy probable que ejerza conductas que puedan confirmarle el sentimiento de superioridad de género inducido por la cultura patriarcal para recuperar así su autoconcepto, su autoestima y su seguridad. En síntesis, en la medida en que la sujeción de las mujeres es asociada con el autocontrol masculino, la violencia contra las mismas es el mecanismo interiorizado en la subjetividad masculina como recurso frente a la crisis de identidad, luego como dispositivo último para la confirmación de la masculinidad hegemónica patriarcal. La violencia masculina es, por lo tanto, un recurso sistémico del orden social que sustenta la masculinidad hegemónica: el patriarcado.

Esta tesis se observa de manera paradigmática en los asesinatos de mujeres que se producen cuando estas deciden romper la relación. Los maltratadores incrementan su nivel de violencia en la medida en que no consiguen obtener el control deseado, lo que frustra su idea de sí mismos, llegando a asesinar a las víctimas, cuando estas no flaquean en su empeño de libertad. Es más, el hecho de que algunos se suiciden después del cometer el crimen muestra que, en ese momento, adquieren conciencia de que realmente eran ellos quienes dependían funcionalmente de las víctimas.

La violencia entre iguales también es una política de confirmación de la masculinidad. Pero la conducta antisocial entre hombres no exime en ningún caso de su ejercicio contra las mujeres, sino que incluso puede potenciarlo. La violencia entre iguales es una práctica que los hombres aprenden a ejercer y

\footnotetext{
${ }^{5}$ Celia Amorós (1992) explicó que la tensión de los pactos patriarcales (la ansiedad resultante de las exigencias de la masculinidad normativa) se proyecta sobre figuras femeninas de exclusión que condicionan la preinterpretación androcéntrica de todas las mujeres.
} 
padecer en su propio cuerpo con resignación, bajo la premisa social de que dicha práctica confiere reconocimiento colectivo (Bourdieu, 2005). Pero la masculinidad siempre está puesta en cuestión, por lo que los pactos patriarcales no generan seguridad, sino constante tensión como resultado de su necesidad de confirmación (Amorós, 1992). Además, este pacto genera asimismo un sentimiento de desprecio hacia las mujeres, puesto que ellas no solo no obtienen reconocimiento a través del ejercicio de la violencia, sino que han sido definidas por la cultura patriarcal como seres débiles que necesitan de protección, lo que, en último término, las convierte en objetos de la economía simbólica de la masculinidad (Segato, 2003). De este modo, frente a la tensión acumulada por la exigencia de virilidad, el patriarcado ha reservado un refugio histórico en el que los hombres confirman una masculinidad definida en términos de dominación: el espacio privado. Solo a través del ejercicio de autoridad sobre las mujeres, obtiene seguridad y autoestima el hombre identificado con la masculinidad hegemónica patriarcal. Solo en el espacio de la intimidad, es capaz de resolver las frustraciones que la necesidad permanente de confirmación de la masculinidad le generan.

La socialización en la pragmática del control produce una fragmentación de la experiencia humana, en la que condiciones como la emotividad, la sensibilidad, la empatía y la vulnerabilidad (en conjunto, todas aquellas que la cultura patriarcal ha inscrito en la femineidad normativa) son negadas, reprimidas y ocultadas por los hombres. Esto genera múltiples frustraciones emocionales en los mismos, quienes no acaban de percibir las limitaciones que la masculinidad supone para su desarrollo humano, puesto que esta sigue ostentando el paradigma normativo de salud, autonomía y madurez en nuestras sociedades contemporáneas (Bonino, 200o). Pero la imposibilidad de reconocer y exteriorizar las emociones no solo limita la capacidad de empatía de los hombres, sino que los dispone a canalizar sus frustraciones a través de la violencia:

Si nunca he aprendido cómo respetar mis propias emociones y sentimientos, y los experimento como signos de debilidad, entonces me va a ser difícil respetar las emociones y los sentimientos de otros (Seidler, 2000: 203).

El disciplinamiento de la emotividad es una de las prácticas constituyentes de la masculinidad patriarcal desde los albores de nuestra cultura occidental. Por ejemplo, Homero le concede a la cólera de Aquiles una función central como desencadenante de la trama en el relato de La Ilíada. La ira es el único 
sentimiento que los hombres pueden expresar. Es el sentimiento de los héroes. Y, como ha señado Bourdieu (2005), los hombres adquirimos la moral social hegemónica aprendiendo a jugar a los juegos sociales de poder, de los cuales el primero es el juego de guerra, simbolizado durante la infancia por la illusio masculina del heroísmo. De hecho, la medida en que los hombres obtienen reconocimiento y privilegios sociales es determinante en la integración o la afloración de las frustraciones masculinas. Es decir, en tanto que identidad definida por la posibilidad de poder social, la obtención de cierto estatus y bienestar sociales palía y oculta las frustraciones generadas por las prácticas de disciplinamiento de la emotividad, como prácticas garantes de la masculinidad exigida. Pero, cuando los hombres no ven socialmente satisfechas las exigencias de la masculinidad normativa, cuando experimentan la sensación de que no alcanzan a satisfacer su idea (interiorizada) de masculinidad, las frustraciones producidas por la pragmática del control emergen, generando inseguridad y tedio vital. En este momento, el recurso más accesible para la confirmación de su masculinidad (y, por ende, para la recuperación del control) está dispuesto por la estructura social patriarcal: las mujeres, culpabilizadas de encarnar las exigencias que el sistema proyecta sobre los hombres, se convertirán en el centro de la ira del héroe, quien termina así transformándose en un monstruo (Gil, 2006).

La crisis masculina se acrecienta cuando los hombres sienten impugnada su posición social patriarcal directamente por las mujeres, bien sea en la vida personal cotidiana, bien a través de reivindicaciones públicas feministas o bien de ambas maneras. La autonomía de las mujeres suele ser percibida como una amenaza hacia su posición, su control y su masculinidad por aquellos hombres identificados con el modelo normativo, puesto que se sienten obstaculizados para desarrollar los roles designados por el mismo, los cuales deberían concederles el estatus de sexo-género reservado a la masculinidad. Este hecho se percibe con claridad en las crisis existenciales que experimentaron los hombres a finales de la década de los ochenta del siglo pasado, cuando las mujeres empezaron a acceder a posiciones laborales hasta ese momento monopolizadas por los hombres (Clare, 2002). Ahora bien, este hecho toma un cariz significativamente distinto en las actuales democracias occidentales, en las que la igualdad legal entre hombres y mujeres debería haber supuesto que los hombres asuman que las mujeres tienen un derecho equitativo al suyo de ocupar el cuerpo social. En nuestro pasado reciente, la sanción violenta de las mujeres que reclamaban más autonomía a manos de sus maridos no era concebida ni como un acto antisocial ni como el resultado de ninguna crisis masculina. La 
autoridad masculina constituía la norma social y la violencia machista no era más que el instrumento legítimo del poder vigente (Lorente, 2001). Actualmente, en nuestras democracias occidentales, tanto la desigualdad de género como las violencias machistas están públicamente condenadas, son políticamente incorrectas y se encuentran sancionadas por la ley. El modelo del hombre protector se manifiesta patentemente disfuncional dentro del orden social democrático. Pero, por debajo de esta ficción de igualdad, el modelo del héroe guerrero sigue siendo el paradigma normativo de masculinidad (Castells y Subirats, 2007). La violencia entre iguales es una constante durante la socialización de los hombres desde su infancia (Castells y Subirats, 2007), llegando a manifestarse en casos dramáticos de bullying escolar, frente a los cuales tanto el padre como la madre del niño siguen experimentado gran dificultad para no incitarle a defenderse ejerciendo violencia. Una vez más, los progenitores se convierten en los agentes inconscientes de la moral androcéntrica masculinista, la moral del honor (Bourdieu, 2005), a partir de su conocimiento pragmático de que un hombre que no sabe defenderse tiene muchas posibilidades de ser excluido socialmente e incluso violentado por sus iguales, quienes no le considerarán digno de ser un hombre; quienes, en palabras de Celia Amorós (1992), actualizarán ad infinitum el pacto patriarcal de fraternidad-terror, confirmando así recurrentemente en serie su masculinidad. La socialización en el ejercicio de la violencia se asienta aún más mediante la práctica de deportes competitivos de equipo, en los que los hombres jóvenes no solo aprenden a disciplinar su cuerpo y sus emociones en aras del objetivo de la victoria, sino que, además, perciben una identificación de la masculinidad con el éxito social, mediada la trascendencia pública y económica que estos deportes tienen actualmente en sus categorías masculinas (Badinter, 1993; Sanfélix, 2020). En estas circunstancias, frente a la mera conciencia ideológica de una cultura democrática de la paz, no es extraño que muchos hombres sigan siendo incapaces de contener su agresividad cuando ven amenazados sus proyectos y objetivos; cuando sienten que han perdido el control sobre algún aspecto de su vida. Esta disposición se incrementa aún más frente a las mujeres, a quienes la cultura patriarcal o bien responsabiliza de las exigencias del propio sistema normativo de masculinidad o bien designa como las traidoras, las brujas; siempre prestas a hacer fracasar la estructura social dispuesta por la fratría de iguales (Amorós, 1992).

En resumen, los hombres occidentales estamos siendo socializados en una contradicción identitaria entre los valores democráticos y los símbolos, los valores y las prácticas de la masculinidad hegemónica patriarcal. Una contradicción que, incardinada en la subjetividad masculina, es fuente de incon- 
gruencia, inestabilidad y frustración, pero también de violencia e injusticia hacia las mujeres. Los hombres somos educados ideológicamente en los principios formales de las sociedades democráticas (libertad, igualdad y solidaridad), al tiempo que socializados en una pragmática masculinista del control y una definición androcéntrica del sujeto de éxito social que, incluso impugnada, nos sigue estimulando para identificarnos como tales (Sambade, 2012). El androcentrismo sigue constituyendo el sesgo cultural normativo, solo que se encuentra oculto e invisibilizado por la ficción de igualdad contemporánea. Esta es proyectada por los medios de comunicación de masas, los cuales representan a hombres y a mujeres a partir de modelos heteronormativos de belleza aparentemente equitativos que simbolizan el éxito social. Pero la dialéctica de las identidades sexuadas ubica a hombres y mujeres en posiciones asimétricas, puesto que ellos siguen siendo definidos como los verdaderos sujetos agentes del relato social compartido, mientras que ellas lo son como los objetos de su deseo sexual (Sambade, 2014). Esta construcción no es inocua ni inocente, pues muestra su connivencia con una de las formas revitalizadas de explotación de las mujeres: el sistema prostitucional y la trata con fines de explotación sexual (De Miguel, 2015).

En síntesis, la estructura patriarcal, aun impugnada, socializa a los hombres en una masculinidad contradictoria que es fruto del conflicto social vigente, un conflicto invisibilizado por la dialéctica simbólica de la contrarreforma patriarcal. Los hombres occidentales del presente experimentan con angustia las exigencias de los pactos androcéntricos de masculinidad, al mismo tiempo que disfrutan de los privilegios que sus modelos de identificación les conceden, concibiéndolos probablemente como resultados de sus méritos y llegando incluso a definirse desde una conciencia igualitaria. Es más, probablemente, la mayoría cree que la igualdad es un hecho y no percibe la inequidad de sus conductas. Esto dispone un sentimiento de frustración y resentimiento frente a las demandas de las mujeres que, si bien se puede observar en la resistencia masculina frente a la denominada cuarta ola de feminismo, tiene su materialización personal en distintas estrategias de control/discriminación de las mismas, desde los micromachismos cotidianos hasta la cruenta realidad de la violencia machista. El maltratador contemporáneo puede definirse a sí mismo incluso como un hombre democrático, pero se muestra incapaz de asumir su necesidad de control y sometimiento. De hecho, en muchas ocasiones, la violencia se justifica en términos de crisis, para acabar responsabilizando a las mujeres de las misma. Estos hombres están integrados en la normalidad social, pero no logran reconocer la dependencia funcional 
que tienen de sus parejas ni siquiera en el momento de la ruptura, cuando se muestran incapaces de controlar su ira y ejercen una coerción violenta contra las mismas. ${ }^{6}$

\section{CONCLUSIÓN}

El proceso de democratización social de las democracias contemporáneas, en concreto su sensibilización contra la discriminación machista, supone una dificultad creciente frente a la confirmación de las expectativas patriarcales de masculinidad por parte de los hombres. Esto causa múltiples frustraciones y conductas disfuncionales en su personalidad, puesto que la socialización en el modelo pragmático normativo de masculinidad sigue vigente, especialmente a través de la estructura de competición-alianza de la fratria (Segato, 2003). Es más, la socialización patriarcal es frustrante de por sí, porque anula gran parte del potencial de desarrollo humano de los hombres por medio del disciplinamiento del cuerpo y de la emotividad. Ahora bien, esto no significa que los hombres, en particular los agresores de mujeres, padezcan algún tipo de enfermedad mental. Todas las personas experimentamos numerosas frustraciones en nuestra vida, muchas de ellas provocadas por las exigencias normativas de género durante el proceso de socialización. Las frustraciones pueden ser gestionadas mediante el desarrollo de prácticas sociales funcionales y adaptativas, o bien ocasionar conductas socialmente disfuncionales. En el caso de los agresores machistas, la violencia es el resultado de una frustración identitaria que no solo refleja el conflicto social vigente, sino también los mecanismos simbólicos que lo invisibilizan. De este modo, la reproducción de las estructuras sociales patriarcales hace que las frustraciones ocasionadas por la socializa-

${ }^{6}$ Esto no significa que los maltratadores machistas ejerzan su violencia de forma descontrolada. Existen diversos perfiles de maltratador machista y, mientras que algunos ejercen su violencia con frialdad y alevosía, otros recurren a ella de modo impulsivo. En este sentido, Miguel Lorente (2001) ha explicado que la violencia que ejercen los maltratadores machistas no es fruto de una enajenación transitoria, sino que más bien responde a una estrategia cuya finalidad concreta es conseguir el sometimiento y el control de sus parejas. La ira contra las mujeres es el resultado de la necesidad de dominación que el orden patriarcal les exige a través de la masculinidad normativa, una necesidad cada vez más frustrada por la conciencia social feminista de las mujeres y sus consiguientes actos de emancipación. Pero el maltratador no ejerce su violencia descontroladamente, sino con frialdad, despotismo y método. El agresor amenaza, menosprecia, golpea y niega, siempre con el objetivo de generar miedo e indefensión en la víctima; siempre con el objetivo de aleccionarla para que se muestre sumisa (Lorente, 2001). Es frecuente que los agresores se muestren arrepentidos y desconsolados tras los primeros sucesos de violencia, pero, a medida que el maltrato se intensifica, estos episodios suelen ser cada vez menos frecuentes y menos duraderos (Walker, 1979). 
ción en la masculinidad hegemónica tengan una respuesta programada de antemano por la cultura machista: el ejercicio de discriminación/dominación de otras personas, especialmente de las mujeres, como recurso para la recuperación del autocontrol y la autoestima. Es decir, la cultura patriarcal normaliza conductas socialmente disfuncionales, predominando aquellas que se originan en el sistema de dominación-sumisión, como estrategias de autocontrol emocional (Lyons-Ruth and Jacobwitz, 2008). Por lo tanto, en última instancia, el protagonismo masculino de las conductas antisociales y de la victimización de las mujeres es el resultado de la reproducción de una configuración patriarcal de masculinidad invisibilizada por la redefinición cosmética que opera la ficción de igualdad contemporánea. En este sentido, debemos tener presente la íntima relación que existe entre los actos concretos de violencia machista y la reproducción del orden patriarcal y su cosmología androcéntrica en el cuerpo social. Ocultos bajo la división público/privado y enmascarados por las inequitativas representaciones de género, los agresores encuentran no solo la posibilidad de disimular sus conductas delictivas, sino también de contar con diversas formas de complicidad social que, por omisión o inadvertencia, refuerzan sus injustas convicciones.

\section{BIBLIOGRAFÍA}

Amorós, Celia (1992). Notas para una teoría nominalista del patriarcado. Asparkía, 1, 41-58. doi: http://dx.doi.org/10.6035/Aspar kia

Badinter, Elisabeth (1993). XY. La identidad masculina. Madrid: Alianza. Bonino, Luís (1998). Micromachismos. la violencia invisible. Madrid: Cecom.

Bonino, Luís (200o). Hombres, género y salud mental: deconstruyendo la normalidad masculina. En Segarra, Marta y Carabí, Ângels (eds.). Nuevas Masculinidades (41-64). Barcelona: Icaria.

Bourdieu, Pierre (2005). La dominación masculina. Barcelona: Anagrama.

Castells, Manuel y Subirats, Marina (2007). Mujeres y hombres: un amor imposible. Madrid: Alianza.

Clare, Anthony (2002). La masculinidad en crisis. Madrid: Taurus. 
Cobo, Rosa (2017). La prostitución en el corazón del capitalismo. Madrid: La Catarata.

Connell, Raewyn (1995). Masculinities. Cambridge: Cambridge Polity Press; Sydney: Allen \& Unwin; Berkeley: University of California Press.

Connell, Raewyn y Masserschimidt, James (2005). Hegemonic Masculinity: Rethinking the Concept. Gender \& Society, 19, 829859.

Connell, Robert W. (1997). La organización social de la masculinidad. En Valdés, Teresa y Olavarría, José (eds.). Masculinidad/es: poder y crisis (31-48). Santiago de Chile: ISIS-FLACSO.

De Alencar-Rodrigues, Roberta y Cantera, Leonor (2012). Violencia de género en la pareja: una revisión teórica. Psico, 43(1), 16-126.

De Miguel, Ana (2015). Neoliberalismo sexual. El mito de la libre elección. Madrid: Cátedra.

Dohmen, Mónica L. (1996). Un perfil de hombre golpeador. En Corsi, Jorge (coord.). Violencia masculina en la pareja. Una aproximación al diagnóstico y a los modelos de intervención (43-130). Barcelona: Paidós.

Dutton, Donald G. y Golant, Susan K. (1997). El golpeador. Un perfil psicológico. Barcelona: Paidós.

Ferreira, Gabriela (1992). Hombres violentos, mujeres maltratadas: aportes a la investigación y tratamiento de un problema social. Buenos Aires: Sudamericana.

Gil, Enrique (2006). Máscaras masculinas. Héroes, patriarcas y monstruos. Barcelona: Anagrama.

Gilmore, David (1994). Hacerse hombre: concepciones culturales de la masculinidad. Barcelona: Paidós.

Gómez, Águeda (2017). Masculinidad y gramática sexual del putero. En Nuño, Laura y De Miguel, Ana (eds.). Elementos para una teoría crítica del sistema prostitucional (143-156). Granada: Comares. 
Gowaty, Patricia A. (2008). Biología y género(s). En Carabí, Àngels y Armengol, Josep M. (eds.). La masculinidad a debate (133-154). Barcelona: Icaria.

Gutierrez-Barroso, Jorge, Barragán-Medero, Fernando y Pérez-Jorge, David (2018). Suicide in Europe Countries. A Multivariate Approach Analysis. Global Journal of Health Science, 10(4), 12-21. doi: https://doi.org/10.5539/gjhs.v1on4p12

Hernández, Carmelo y Cuellar, José Pablo (2019). Enfoque de género y masculinidades en la intervención psicocriminológica con agresores de género en medio abierto. En Martínez, Javier Eloy, Téllez, Anastasia y Sanfélix, Joan (eds.). Deconstruyendo la masculinidad. Cultura, género e identidad (267-290). Valencia: Tirant Humanidades.

Lorente, Miguel (2001). Mi marido me pega lo normal. Agresión a la mujer: realidades y mitos. Barcelona: Ares y Mares.

Lorente, Miguel (2009). Los nuevos hombres nuevos. Barcelona: Destino. Lyons-Ruth, Karlen y Jacobvitz, Deborah (2008). Attachment Disorganization: Genetic Factors, Parenting Contexts, and Developmental Transformation from Infancy to Adulthood. En Cassidy, Jude y Shaver, Phill (eds.). Handbook of Attachment: Theory, Research, and Clinical Applications (666-697). New York: Guilford Press.

Marqués, Josep V. y Osborne, Raquel (1991). Sexualidad y sexismo. Madrid: UNED-Fundación Universidad-Empresa.

Plumwood, Val (1993). Feminism and the Mastery of Nature. London, New York: Routledge.

Puleo, Alicia H. (2012). Contrarreforma patriarcal en nombre de la ecología. Revista mientras tanto, 105. Recuperado de: http://www.mientrastanto.org/boletin-105/notas/contrarreformapatriarcal-en-nombre-de-la-ecologia [Consultado el 16 de junio de 2021].

Sambade, Iván (2012). Medios de comunicación, corporeidad masculina y desigualdad de género en las democracias 
occidentales. En Pérez Sedeño, Eulalia e Ibáñez Martín, Rebeca (eds.). Cuerpos y diferencias (271-291). Madrid: Plaza y Valdés. Sambade, Iván (2014). Sobre las contradicciones de la razón moderna y la constitución de la subjetividad masculina. Prisma Social, 13, $787-851$.

Sambade, Iván (2020). Masculinidades, violencia e igualdad. El (auto)control de los hombres como estrategia de poder social. Valladolid: Ediciones Universidad de Valladolid.

Sanfélix, Joan (2020). La brújula rota de la masculinidad. Valencia: Tirant Humanidades.

Sapolsky, Robert (1997). The Trouble with Testosterone and Other Essays.

New York: Simon\&Shuster.

Segal, Lynne (2008). Los hombres tras el feminismo ¿Qué queda por decir? En Carabí, Àngels y Armengol, Josep M. (eds.). La masculinidad a debate (155-177). Barcelona: Icaria.

Segato, Rita L. (2003). Las estructuras elementales de la violencia. Bernal:

Universidad Nacional de Quilmes.

Seidler, Victor (2000). La sinrazón masculina. México: Paidós-UNAM.

Valcárcel, Amelia (2008). Feminismo en el mundo global. Madrid: Cátedra.

Walker, Leonore E. (1979). The Battered Woman Syndrome. New York: Harper and Row.

Walter, Natasha (2010). Muñecas vivientes. El regreso del sexismo. Madrid: Turner. 